\title{
Design, implementation and evaluation of an authentic assessment experience in a pharmacy course: are students getting it?
}

\section{Serrano Santos, Jose Manuel ${ }^{\mathrm{a}}$}

${ }^{a}$ Pharmacy, School of Clinical Sciences, Queensland University of Technology, Brisbane, Australia.

\begin{abstract}
Authentic assessment has been a focal strategy in higher education as a way to provide students with engaging and meaningful learning experiences in preparation for the real world work environments. Possibly due to the lack of consensus in the elements that outline that authenticity, limited amount of authentic learning experiences are reported and evaluated in the literature. This study aims to describe and evaluate the design and implementation of an authentic assessment in a pharmacy undergraduate course. A fivedimensional model for authentic instruction was utilized in the design of the learning experience. This was complemented with an eight-element framework that contributed to create an authentic assessment. Two surveys explored subjective authenticity as perceived by students and stakeholders. The results revealed that students found it hard to value their performance at the higher level that stakeholders do. While the use of models and frameworks in the design of authentic assessment is valuable, academics' efforts need to be concentrated on further developing student's metacognitive skills in order to provide relevancy and value to the knowledge, skills and attitudes developed in undergraduate tertiary education.
\end{abstract}

Keywords: Authentic Assessment, Authentic Learning, Pharmacy education, assessment design 


\section{Introduction}

The topic of authentic learning and assessment has been a strong focus of attention in higher education in the last two decades. (Ashford-Rowe et al., 2014; Meyers \& Nulty, 2009) It is believed that authentic learning and assessment provide learners with engaging and meaningful learning experiences that connect their learning and performance to real world work environments. Theoretically, these experiences provide the students with conceptual connections that contribute to learner's readiness and employability in the work environment.

It is also essential to recognise that the design of authentic assessment requires a course approach and needs to be supported by a pedagogical framework that aligns with the industry expectations.(Ashford-Rowe et al., 2014) Higher education practice has been significantly influenced by the constructivist learning theory and the instructional design literature. (Biggs, 1996) This lines of thinking, are usually combined into one approach referred as "Constructive alignment" that brings together instruction, learning and assessment. (Biggs, 1996) (Gulikers, Bastiaens, \& Kirschner, 2004).

Contemporary education approaches have focused on developing the skills and abilities of students, and these are often aligned with principles from Social Constructivism and Connectivism (Hunt \& Chalmers, 2012). Work integrated learning (WIL) plays a crucial role in this teaching approaches and is internationally recognised as "a strategy for ensuring students are exposed to authentic learning experiences" (Ferns, Campbell, \& Zegwaard, 2014). WIL experiences provide the students with the opportunity to apply theoretical concepts to practice-based tasks, ultimately enhancing graduate employability (Knight \& Yorke, 2004) (Peach \& Matthews, 2011).

Despite the extensive conversations about what makes an assessment authentic and the numerous frameworks that identify the critical elements of authentic assessment, there is not always consensus in the components that shape the authenticity of learning and assessment experiences. A thorough literature review carried out by Gulikers et al (Gulikers et al., 2004) identified three principles that grounded the design of a five-dimensional framework for authentic assessment. These principles highlight the importance of alignment to authentic instruction that influence student learning, demonstration of competences thought a valuable accomplishment and the acknowledgment of authenticity as subjective perception to the student. Recent work by Ashford-Rowe et al (Ashford-Rowe et al., 2014) outlined eight elements that are considered critical in the design of authentic assessment. These could be summarised as: i. Challenge, ii. Performance, iii. Transfer of learning, iv. Metacognition, v. Accuracy, vi. Fidelity, vii. Discussion and feedback, and viii. Collaboration. 
Teaching and learning approaches used in pharmacy education in Australia have experienced considerable change over the past decade (Marriott et al., 2008). Current reforms of the curricula focus on the graduates acquiring not only knowledge but also the abilities, attitudes and skills that society demands as essential in healthcare professional (Blackmore \& Kandiko, 2012). The development of competencies in the contemporary design of curricula promote an interdisciplinary and professional identity development (Langendyk, Mason, \& Wang, 2016). Queensland University of Technology has established authentic assessment that is designed and evidenced at the whole-of-course level as a distinguishing feature of learning. As learners advance from introductory through to developmental and mastery levels, QUT course designs are encouraged to ensure that learners engage progressively with authentic assessment tasks and activities, supported by authentic learning and pedagogy across their learning journey. The review of a pharmacy curriculum provided the opportunity of reflecting on the implementation of authentic assessment and the perceptions of students and stakeholders. This study aims to describe and evaluate the design and implementation of an assessment supported by authentic instruction and a framework of nine components of authenticity in the context of a pharmacy undergraduate course.

\section{Methods}

The review of a particular unit in the pharmacy course provided the opportunity to design an assessment where students could demonstrate core professional competences within evidence-based practice focused on the patient care in order to solve practical and clinical problems in a real world pharmacy setting. In this particular unit, a strong focus was expected in research and communications skills. Students in the $4^{\text {th }}$ year of Pharmacy in QUT are expected to further develop professional skills under the guidance of preceptor pharmacists with the aim of enhancing the understanding of the role of the pharmacist in providing healthcare products and advice to patients. Exposure to real life clinical scenarios in WIL activities was expected to further develop their analytical and problem solving abilities in providing both pharmacological and non-pharmacological healthcare solutions.

A backward design process (Wiggins \& McTighe, 2001) was selected in the design of this unit and its assessment. A poster presentation as part of a health conference was identified as an appropriate demonstration of the targeted learning outcomes while still providing an authentic environment for assessment. Participating in scientific conferences are often considered an expectation in the professional life of clinicians.as these events provide a unique opportunity to disseminate knowledge involving visual and verbal communication as well as to demonstrate research skills and high order critical thinking. 


\subsection{Authentic instruction}

Following the five-dimensional model for authentic instruction (Gulikers et al., 2004), the unit was designed components that safeguarded authentic learning goals:

\subsubsection{Authentic learning tasks}

Undergraduate students are not always familiarised with conference setting and "hands-on" research activities. Therefore the unit structure was divided in two parts, one where the students would interact with an experienced academic and scaffold their learning in preparation for the conference, and a second part where the students could carry out a small research project in a pharmacy setting as a WIL experience. Numerous tasks were developed during the first part of the unit to provide the relevancy and the value of this learning experience to the students. This included tasks like identifying health problems and relate them to available evidenced solutions, questionnaire and poster design, peer feedback and strategies for effective communication.

\subsubsection{Authentic and social learning context}

The combination of in-class collaborative interaction with on-field research data collection provided a safe learning environment but also reflected the way that knowledge, skills and attitudes were used in professional practice with relevancy to a health conference. It is widely recognised that collaborative learning is also an essential part of authentic learning (Herrington \& Herrington, 1998), however, the independency and individual accountability of the learner also needs to be considered (Slavin, 1989) as uniquely discussed in the fivedimensional framework. Hence, an individual self-assessment of performance was encouraged as part of the WIL task with guidance from the preceptor on site.

\subsubsection{Epistemology of the practitioner and authentic learning goals.}

During the on-campus part of the learning, the academic facilitated activities that encouraged the critical thinking skill of the students in a research environment. In-class support from other specialised resources (database searches, software support for poster design and oral communication skills) was facilitated utilising the internal network of the university to support the students. 


\subsection{Assessment design and implementation}

Within one week of completing the WIL experience, the students were asked to submit a research abstract to the unit coordinator. This resembled the usual abstract submission expected in scientific conferences and provided a connection to previous knowledge.

Those students assessed were expected to create a poster that highlighted not only their research but also a solution in the shape of a Health campaign or pharmacy intervention that contributed to solve the Health problem identified in practice. Each of the posters were presented in a digital format in a conference room followed by 15 minutes oral presentations from professional researchers in order to facilitate the physical and social context where research happens.

The assessment criteria explored the background research presented, the link with the health campaign ad level of understanding of the topic, the use of theoretical frameworks to the design, and the oral and visual communication of the content. Members of the pharmacy profession from hospital, industry and community settings were invited to attend to the conference and act as assessors of the posters.

\subsection{Results: Evaluation of the assessment experience}

Several authors highlight how the authenticity of an assessment is subjective to each student.(Gulikers et al., 2004; Honebein, Duffy, \& Fishman, 1993; Huang, 2002). Hence it was important to explore the perceptions of the students and the assessors on the relevancy of this assessment in the career of a pharmacist.

\subsubsection{Survey of students and stakeholders}

A survey was designed to explore the perception of the students on the demonstration of research skills, relevancy of the skills acquired and the level of performance in this unit as well as their confidence on communicating with members of the audience. A similar survey was designed for the assessors, but this one also included a question about how confident they would feel when recommending the students for employment. The surveys were carried out online within a week after the event. Ethical approval to survey this sample of students and assessors was granted by the Human Research Ethics Committee in QUT.

Participation to the survey was voluntary. A total of 14 students $(34 \%)$ out of 41 , and 6 assessors (46\%) out of the 13 that took part in the conference completed the surveys. Across all questions, students perceived a lower level of performance in the assessment and their demonstration of skills than that one perceived by the assessors (Figure 1 and Figure 2). This difference was particularly substantial in the relevancy of their skills but also in self-assessment skills (metacognitive skills). This was also apparent in some of the comments added by the participants: "The enthusiasm and application of the students in 
presenting created an uplifting experience for observers and judges. " (Assessor A), "I am very impressed from the high performing cohort provided by QUT as future pharmacists." (Assessor B), "It is a good day for networking" (Student A), "I didn't really think that it aided awareness of what employees are looking for. "' (Student B)

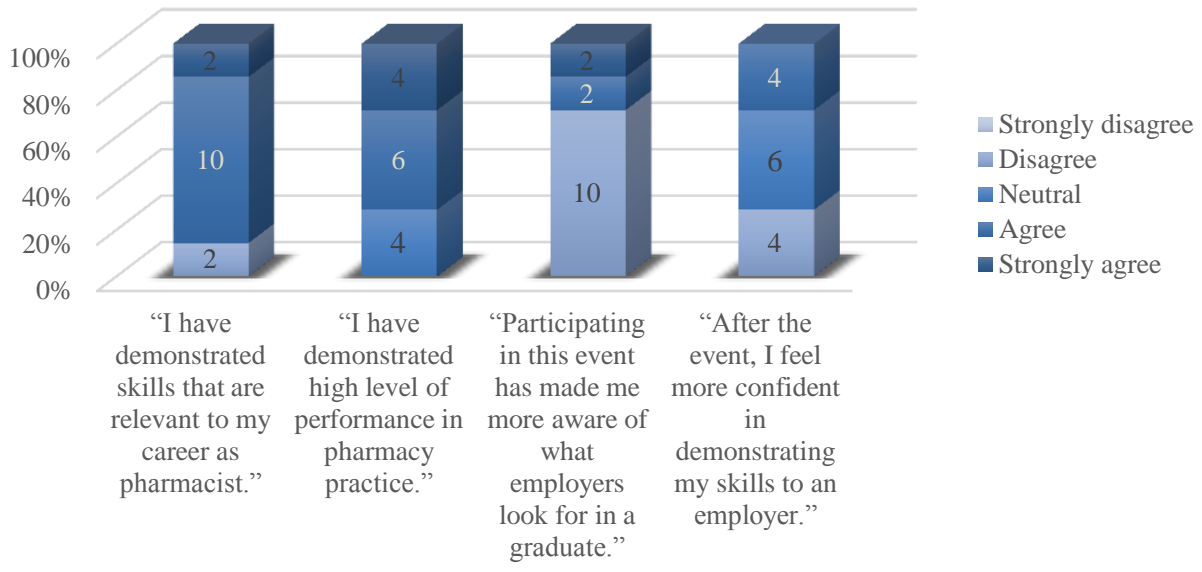

Figure 1: Students' perceptions on the authenticity of the assessment

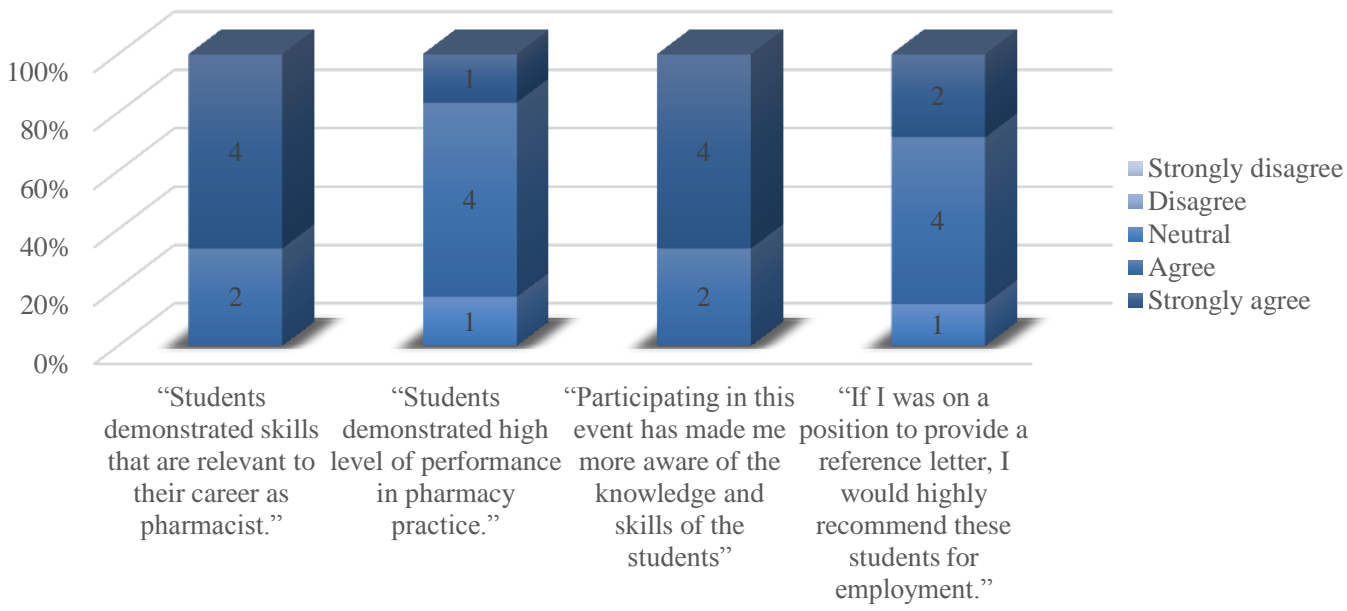

Figure 2: Assessors' perceptions on the authenticity of the assessment 


\section{Discussion}

\subsection{Challenging the students and their performance}

As students progress through an undergraduate course, they face a variety of assessments that may challenge their performance. In this case, the task required the synthesis of a range of skills and information into the composition of an appropriate performance. The final outcome was core part of their unit and it shaped the authenticity of the instruction by facilitating those skills that are applied in a simulated environment. The student participants did not highly valued the creation of a poster as authentic skills, in contrast to previous literature where students perceived the development of a final product as a valid determinant of authentic assessment.(Ashford-Rowe et al., 2014) This result can indicate the challenge found by the students when implementing authentic assessment, possibly due to previous instruction trough traditional assessments based on behaviourist philosophies. (Merriam \& Bierema, 2014; Westbrook et al., 2013).

\subsection{Transfer of learning}

While the transfer of learning seemed obvious for the assessors, it seems necessary to confirm to the learners the authenticity and relevancy of their knowledge, attitudes and skills that society demands as essential in healthcare professionals (Blackmore \& Kandiko, 2012). Collaboration in interdisciplinary groups is also necessary to facilitate this transfer of learning. (Frenk et al., 2010; Horton, 2010).

\subsection{Metacognition}

Metacognitive skills were demonstrated through critical reflection and peer evaluation in the first part of the learning activities and through self-assessment during the WIL activity. While it is possible that time constrains or lack of experience may have compromised certain level self-reflection of their performance, the assessors believed in the authenticity and the relevancy of the skills demonstrated by the students. This fact indicates that academics should focus further efforts into developing the reflective skills of our students to advance their educational practice.

\subsection{Accuracy and fidelity in a collaborative environment}

The environmental context in which the assessment was implemented replicated with high fidelity that one of a public scientific conference. This was nevertheless constraint by the requirements of an assessment such as the essential attendance as well as by the shorter timeframes for preparation due to the limited amount time between completion of the WIL activity and the assessment. While this case reported the experiences of a cohort of pharmacy students, this activity could be applicable to the majority of disciplines in tertiary education as it represents a measurement of performance in research and communication 
skills in those industries where the stakeholders are also employers within than profession. The fact that external members of the pharmacy profession acted as assessors provided the students with the opportunity of a feedback session on their posters with the academic in charge of the unit as well as to obtain some feedback from their peers before the final presentation. This contributed to the collaborative nature of authentic assessment identified in the literature (Herrington \& Herrington, 1998) which was already implemented during the first part of the learning activities.

\subsection{Feedback and discussion in authentic assessment}

The results from the evaluation of this assessment agreed with those principles outlined by Gulikers et al (Gulikers et al., 2004), and in particular with the subjectivity of authentic assessment from the perceptions of students. It is difficult to identify if the epistemological standpoint of the accuracy of authenticity belongs to those performing or those assessing, but this reform in assessment has emerged as an academic response to the demands of the industry and the need to equip graduates with the necessary abilities and leadership skills to face the challenges of workforce, such as working in interdisciplinary teams care (McLaughlin, Dean, Mumper, Blouin, \& Roth, 2013).

\section{Conclusion}

While the use of models and frameworks in the design of authentic assessment is valuable, academics' efforts need to be concentrated on further developing student's metacognitive skills in order to provide relevancy and value to the knowledge, skills and attitudes developed in undergraduate tertiary education. This study has contributed to provide experiences and examples of how to implement authentic assessment in the class. The evaluation played a significant role in the iterative process of continuous review of curriculum and, hence, a comparison of the evaluation presented and future evaluations that reflected on these results could be very valuable to refine the authenticity and environment provided in this type of assessments. Further research incorporating focus groups or a larger group of participants would potentially benefit the interpretation of the results. 


\section{References}

Ashford-Rowe, K., Herrington, J., \& Brown, C. (2014). Establishing the critical elements that determine authentic assessment. Assessment \& Evaluation in Higher Education, 39(2), 205-222.

Biggs, J. (1996). Enhancing teaching through constructive alignment. Higher Education, 32(3), 347-364.

Blackmore, P., \& Kandiko, C. B. (2012). Strategic Curriculum Change: global trends in universities. Thousand Oaks: SAGE Publications, Inc.

Ferns, S., Campbell, M., \& Zegwaard, K. E. (2014). Work integrated learning.

Gulikers, J. T. M., Bastiaens, T. J., \& Kirschner, P. A. (2004). A five-dimensional framework for authentic assessment. Educational Technology Research and Development, 52(3), 67.

Herrington, J., \& Herrington, A. (1998). Authentic assessment and multimedia: How university students respond to a model of authentic assessment. Higher Education Research \& Development, 17(3), 305-322.

Honebein, P. C., Duffy, T. M., \& Fishman, B. J. (1993). Constructivism and the design of learning environments: Context and authentic activities for learning. In Designing environments for constructive learning (pp. 87-108): Springer.

Horton, R. (2010). A new epoch for health professionals' education. The Lancet, 376(9756), 1875-1877.

Huang, H. M. (2002). Toward constructivism for adult learners in online learning environments. British Journal of Educational Technology, 33(1), 27-37.

Knight, P., \& Yorke, M. (2004). Learning, curriculum and employability in higher education: Psychology Press.

Langendyk, V., Mason, G., \& Wang, S. (2016). How do medical educators design a curriculum that facilitates student learning about professionalism? International Journal of Medical Education, 7, 32-43. doi:10.5116/ijme.5683.c2e0

Marriott, J. L., Nation, R. L., Roller, L., Costelloe, M., Galbraith, K., Stewart, P., \& Charman, W. N. (2008). Pharmacy education in the context of Australian practice. American Journal of Pharmaceutical Education, 72(6), 131.

McLaughlin, J. E., Dean, M. J., Mumper, R. J., Blouin, R. A., \& Roth, M. T. (2013). A roadmap for educational research in pharmacy. American Journal of Pharmaceutical Education, 77(10), 218.

Merriam, S. B., \& Bierema, L. L. (2014). Adult Learning: Linking Theory and Practice (Vol. 1;). San Francisco, CA: Jossey Bass Ltd.

Meyers, N. M., \& Nulty, D. D. (2009). How to use (five) curriculum design principles to align authentic learning environments, assessment, students' approaches to thinking and learning outcomes. Assessment \& Evaluation in Higher Education, 34(5), 565-577.

Peach, D., \& Matthews, J. H. (2011). Work integrated learning for life: Encouraging agentic engagement.

Slavin, R. E. (1989). Research on cooperative learning: An international perspective. Scandinavian Journal of Educational Research, 33(4), 231-243. 
Westbrook, J., Durrani, N., Brown, R., Orr, D., Pryor, J., Boddy, J., \& Salvi, F. (2013). Pedagogy, curriculum, teaching practices and teacher education in developing countries. Education rigorous literature review.

Wiggins, G., \& McTighe, J. (2001). What is backward design? Understanding by design, 719. 